\title{
Non-catalytic NOx reduction for marine Diesel engine: an experimental approach
}

\author{
Anna Maria Raspolli Galletti ${ }^{1}$, Stefano Frigo $^{2}$, Marco Antonelli ${ }^{*}$, Gianluca Pasini $^{2}$, \\ Paolo Bertetti ${ }^{3}$, Federico Tocchi ${ }^{3}$ \\ ${ }^{1}$ Dipartimento di Chimica e Chimica Industriale (DCCI) - Università di Pisa \\ 2 Dipartimento di Ingegneria dell'Energia, dei Sistemi, del Territorio e delle Costruzioni (DESTEC) - \\ Università di Pisa \\ ${ }^{3}$ Sanlorenzo s.p.a. - Viale San Bartolomeo, 36219126 La Spezia, SP, Italy
}

\begin{abstract}
Recent legislation concerning air pollutant emissions from ships (Tier III) has considerably decreased NOx emission limits for recreational ships with less than 500 gross tonnages and greater than $24 \mathrm{~m}$ load line length (LLL), the so-called "large yachts". For these yachts, which adopt multiple Diesel engines with maximum power ranging from 800 to 2000 $\mathrm{kW}$, the new NOx limit is less than $2 \mathrm{~g} / \mathrm{kWh}$. To satisfy that limit, engine makers suggest the adoption of a classic SCR system with urea injection but this methodology, in addition to requiring a large space for installation, does not seem so appropriate for diesel engines of large yachts that normally operate at low power with exhaust temperatures often well below $300{ }^{\circ} \mathrm{C}$, therefore not sufficient to allow the correct functioning of the SCR. The aforementioned circumstances have prompted Sanlorenzo Spa (La Spezia Italy), one of the world's leading companies in the production of pleasure boats, to collaborate with the University of Pisa in the study of alternative solutions to SCR systems. Recently there is a great interest in innovative NOx abatement systems, based on the possibility of absorbing NOx molecules into seawater through the utilization of appropriate aqueous solutions containing targeted saline oxidizing agents. The present study describes the first results of a research program aimed to identify, from one side, the best saline oxidizing agent for an aqueous NOx abatement and, from the other, the best washing methodology compatible with the propulsion layouts usually adopted on yachts. In the engine testing laboratories of the Department of Energy, Systems, Territory and Construction Engineering (DESTeC) of the University of Pisa, an experimental apparatus has been created to reproduce the real conditions of underwater engine exhausting. This device was combined with a small 1.2 $\mathrm{L}$ direct injection diesel engine. The first results showed a reduction of the NOx emissions of about $27 \%$ by using a gas washing with wet scrubber, followed by bubbling in water, using 0.2 molar $\mathrm{NaClO}$ saline solutions.
\end{abstract}

\footnotetext{
* corresponding author: marco.antonelli@unipi.it
} 


\section{Introduction}

In 1973, the International Maritime Organisation (IMO) adopted the MARPOL (Marine Pollution) Convention which addresses pollution from ships. Within the MARPOL Convention, an annex (Annex VI) was adopted in 1997, which focused on the prevention of air pollution from ships by aiming to reduce SOx emissions, NOx emissions, and greenhouse gases (GHG).

Since the first adoption of Annex VI, there have been several revisions to progressively reduce the NOx emissions from marine diesel engines. With the recent Tier III legislation, implemented starting from the 1st of January 2021 also in the North and Baltic Sea, IMO NOx limits were reduced further and applied also to recreational ships with less than 500 gross tonnages (GT) and greater than $24 \mathrm{~m}$ load line length (LLL), the so-called "large yachts". For these yachts, which adopt multiple Diesel engines with maximum power ranging from 800 to $2000 \mathrm{~kW}$, the new NOx limit is less than $2 \mathrm{~g} / \mathrm{kWh}$ [1]. Figure 1 shows Tier legislation evolution in the last years.

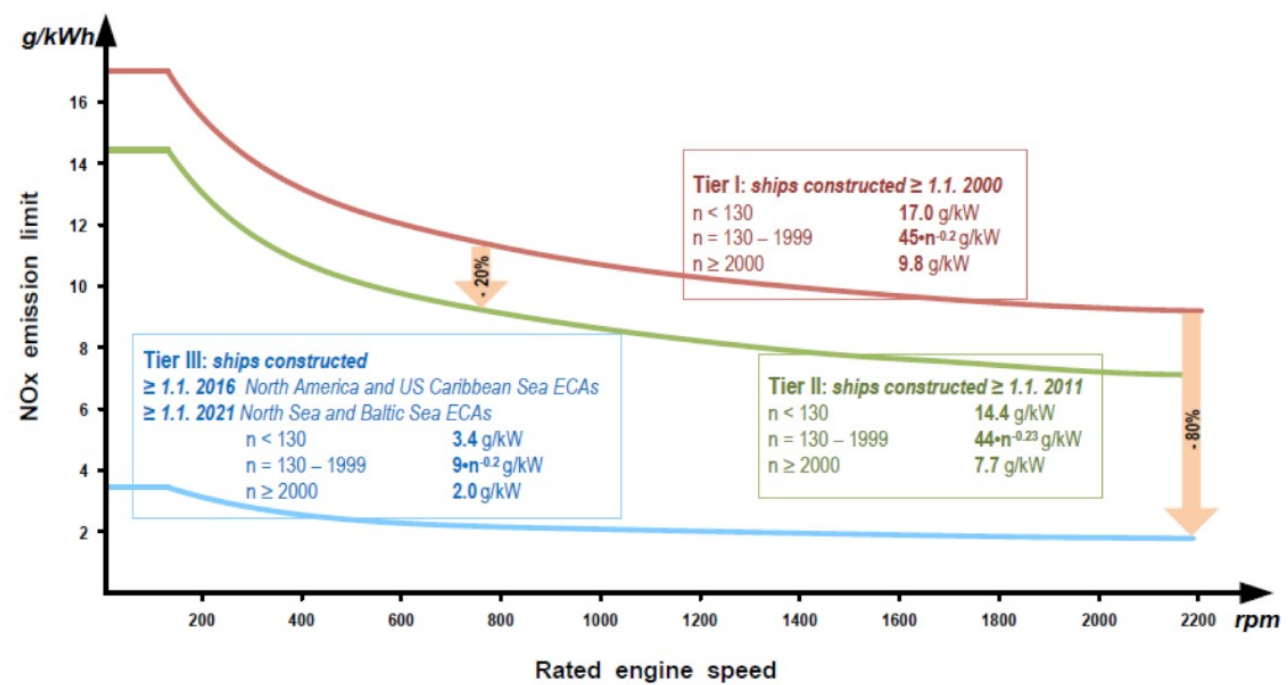

Fig. 1: Tier legislation evolution in the last years.

To satisfy this limit, engine makers suggest the adoption of a classic SCR system with urea injection. This system requires a large volume for installation and does not seem so appropriate for large yachts Diesel engines which usually operate at low power with exhaust temperature often below $300{ }^{\circ} \mathrm{C}$, therefore not enough to allow SCR proper operation. Table 1 reports a comparison of the operating parameters between a large container ship and a $30 \mathrm{~m}$ yacht (most successful size in the category $>24 \mathrm{~m}$ and $<500 \mathrm{GT}$ ). Reported values reveal a different use between large commercial vessels and pleasure yachts smaller than 50 meters (average engine load, power per ton, annual navigation hours, annual engine operating hours), therefore the use of SCR systems involves, on this specific type of ship, contraindications in terms of higher $\mathrm{CO} 2$ emissions, very little real impact in the reduction of NOx and possible release of ammonia vapors in cold catalyst conditions. 
Table 1: comparison of the operating parameters between a large container ship and a 30m yacht

\begin{tabular}{|l|c|c|c|c|c|}
\hline \multicolumn{1}{|c|}{ Ship } & $\begin{array}{c}\text { LLL } \\
{[\mathbf{m}]}\end{array}$ & $\begin{array}{c}\text { Engine } \\
\text { Power/GT } \\
{[\mathbf{h p} / \text { Ton] }}\end{array}$ & $\begin{array}{c}\text { Average } \\
\text { Speed } \\
{[\text { Knots] }}\end{array}$ & $\begin{array}{c}\text { Average } \\
\text { Engine Load } \\
{[\% \text { of Pmax] }}\end{array}$ & $\begin{array}{c}\text { Annual Use } \\
{[\text { [hour] }}\end{array}$ \\
\hline $\begin{array}{l}\text { Large Container } \\
\text { Ship }\end{array}$ & 400 & $0,4-0,6$ & 20 & $70-75$ & $6000-7000$ \\
\hline Yacht & 30 & $45-50$ & $12-20$ & $24-35$ & $200-400$ \\
\hline
\end{tabular}

The aforementioned circumstances have led Sanlorenzo Spa, one of the world's leading companies in the production of pleasure boats, and the University of Pisa to collaborate in the study of alternative solutions to SCR systems.

Recently there is a great interest in innovative NOx abatement systems, based on the possibility of absorbing NOx molecules into seawater through the utilization of appropriate aqueous solutions containing saline oxidizing agents, as evidenced by several scientific papers [2-5]. In fact, NO represents the majority of NOx emissions and has low solubility in water. It is therefore very difficult to break it down with an aqueous abatement (wet scrubber) without being first oxidized into highly water-soluble oxides such as $\mathrm{NO}_{2}, \mathrm{NO}_{3}, \mathrm{NO}_{4}$, and $\mathrm{NO}_{5}$.

To effectively use a scrubber system, it is, therefore, necessary to convert the NO contained in the exhaust gases into nitrogen oxides with a higher oxidation state and much more easily solubilizable. This denitration method, once optimized, can be particularly suitable for controlling emissions from marine diesel engines, thanks to the low operating costs and the versatility of appropriately sized scrubber units. Studies with various oxidizing agents [3] have been reported in the literature, including hydrogen peroxide, Fenton oxidants [4], ozone $[5,6]$, potassium permanganate, and others. In the presence of a basic aqueous phase, both the soluble oxides and the acids are transformed into sodium nitrites and nitrates that can be discharged directly into the sea (provided they are diluted in $\%$ and are not harmful to the ecosystem).

For large yachts, considering the limited volumes available and the safety requirements, the choice of an oxidizing agent (for wet absorption) must meet fundamental requirements, such as easy availability of supply at reasonable costs, high oxidizing efficiency, and good environmental sustainability. A low-cost and widely available oxidizing agent is the very common sodium hypochlorite, $\mathrm{NaClO}$. Many studies highlighted the positive role of basicity on the efficiency of this oxidizing agent $[6,7]$. Among the oxidizing agents, sodium chlorite, $\mathrm{NaClO}_{2}$ [8] is also interesting. Figure 2 shows the effect of the concentration of different oxidants on the NOx absorption efficiency in a basic environment [6].

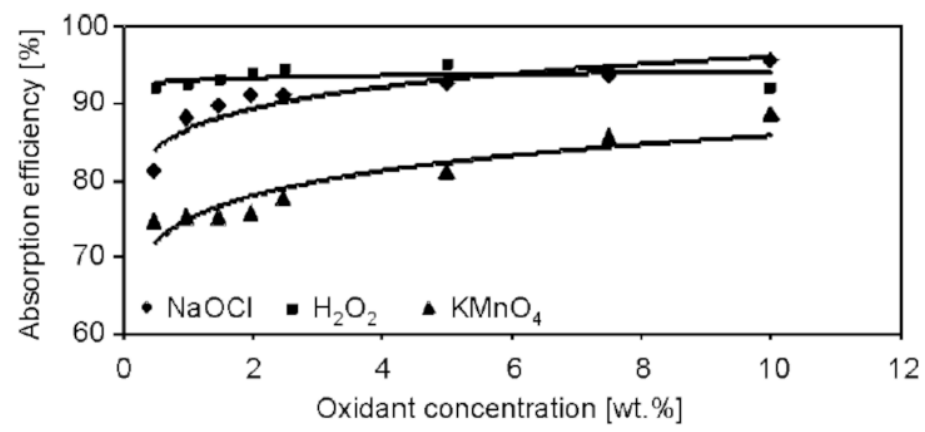

Fig. 2: Effect of the concentration of different oxidants on the NOx absorption efficiency in a basic environment [6]. 
NOx abatement efficiency is influenced by the concentration of the oxidizing agent, which must be kept sufficiently high. Other important reaction parameters are the $\mathrm{pH}$ and salinity of the absorbent medium. The most recent studies show how the balance of these parameters allows optimizing the abatement process up to the complete removal of NOx.

Other recent studies [9] reported the use of aqueous oxidizing solutions of sodium persulfate, $\mathrm{Na}_{2} \mathrm{~S}_{2} \mathrm{O}_{8}$, one more once chosen for its economy, environmental sustainability, and high oxidizing power. The abatement efficiency is significantly influenced by various parameters such as the concentration of the salt, the $\mathrm{pH}$ of the medium, the contact time, the geometry of the scrubber, and the temperature.

Another possible innovative integration with this non-catalytic abatement approach is the eutectic solvents (Deep Eutectic Solvents, or DES). These recently proposed solvents are eutectic mixtures of two solids (or of a solid and a liquid) with a melting point much lower than one of the two isolated components $[10,11]$. Among their most interesting properties are the very low vapor pressure, the high thermal stability, the wide possibility of modulating their chemical-physical properties, non-toxicity, and biodegradability [12], especially when DES are products obtained from natural substances (carbohydrates, amino acids, fatty acids). In addition to their prevalent use as eco-sustainable solvents for organic reactions, they have been used very recently in very few studies also to lower the sulfur and nitrogen content of fuels [13], thus reducing SOx and NOx emissions in a pre-combustion strategy, or to oxidize NOx in exhaust gases (post-combustion strategy).

The present study describes the first results of a research program aimed to identify, from one side, the best saline oxidizing agent for an aqueous NOx abatement and, from the other, the best washing methodology compatible with the propulsion layouts usually adopted onboard yachts.

In the engine testing laboratories of the Department of Energy, Systems, Territory and Construction Engineering (DESTeC) of the University of Pisa, an experimental apparatus has been created to reproduce the real conditions of underwater engine exhausting. This device was combined with a small 1.2 L direct injection diesel engine.

\section{Methodology}

To verify the effectiveness of a NOx abatement system based on exhaust gases washing with aqueous saline solutions, an experimental activity was set up at the DESTEC motor testing laboratory. The Diesel engine utilized is a direct injection, twin-cylinder unit of about 1.251 displacement, manufactured by Lombardini-Kohler (model 9-LD 625-2), whose characteristics are shown in Table 2.

The indicated cycle, the fuel consumption, and the particulate emissions were not acquired, since the main objective of the research was to analyze the effectiveness of NOx abatement systems. In addition, no modifications were carried out to the engine, so that its performance and consumption practically remained unchanged. The data acquisition concerned power and torque and the level of gas pollutants in the conditions of maximum power at various engine speeds. In particular, the engine has been coupled with a Borghi \& Saveri eddy current brake with rpm/torque controller, while for exhaust analysis an Environnement SA test bench, equipped with a Non-Dispersive Infra-Red (NDIR) Sensor, a paramagnetic sensor, a Heated Chemiluminescence Detector (HCLD) and a Heated Flame Ionization Detector (HFID) was employed. Many exhaust gas K-type thermocouples were used to verify the occurrence of the steady-state condition for each different condition employed as a test. 
Table 2: experimental engine characteristics

\begin{tabular}{|c|c|}
\hline Engine type & Lombardini LD 625/2 \\
\hline Number of cylinders & 2 \\
\hline Cooling system & Forced air \\
\hline Displacement [cm $\left.{ }^{\mathbf{3}}\right]$ & 1248 \\
\hline Bore [mm] & 95 \\
\hline Stroke [mm] & 88 \\
\hline Compression ratio & $17.5: 1$ \\
\hline Max rotational speed [rpm] & 3000 \\
\hline Power @ 3000 rpm [kW] & 21 \\
\hline Max Torque @ 2200 rpm [Nm] & 29.4 \\
\hline Fuel injection system & Direct-Mechanic \\
\hline
\end{tabular}

To reproduce, as far as possible, the real operating conditions of the engines used on the reference yachts, a washing system has been conceived and built. The system is composed of a tank, to allow the exhaust gases to bubble, and a "wet scrubber". The bubbling tank is necessary to reproduce the real conditions that occur at the exhaust of large yachts because, before being released into the atmosphere, the engine exhaust gases are conveyed under the hull at a distance of about $50 \mathrm{~cm}$ from the waterline. The scrubber was designed following the indications reported in the dedicated scientific literature [14-17].

However, the overall system has been designed to be flexible as regards the possibility or not of reproducing different operating conditions (presence or absence of scrubber washing, presence or absence of backpressure at the exhaust, etc.).

The final device is composed of a sealed metal tank, with a capacity of about 250 liters, and a washing column of the "scrubber" type with a height of about $1 \mathrm{~m}$ inserted in the upper part. In the tank, where the gases are bubbled through a special pipe, water continuously flows through a feed pump that draws from two 1000 liters tanks located outside the testing room. A second pump is used to take water from the washing tank (emptying pump) and continuously bring it back to the external tanks. By adjusting the flow rate of the feed pump and the emptying pump, it is possible to adjust the water level inside the tank. This level has been set to maintain a liquid head, at the outlet of the bubbling tube, equal to $50 \mathrm{~cm}$. The sprays of the scrubber are fed with another dedicated pump that takes the saline solution from an additional tank. The conceptual scheme of this system is shown in Figure 3.

Pollutant emissions were measured in different points of the washing system:

- $\quad$ point (1) at the engine output to measure initial raw emissions;

- $\quad$ point (2) after the scrubber to identify the influence of scrubbing;

- $\quad$ point (3) at the final outlet to measure the overall effectiveness of scrubbing and bubbling and the influence of only bubbling (when scrubber's nozzles are not activated).

Tests were carried out at full power and different engine speed (1500-2000-2500 rpm). For each operating condition, two series of tests were carried out and the water circuit was completely renovated (total replacement of 2000 liters) between each test. 


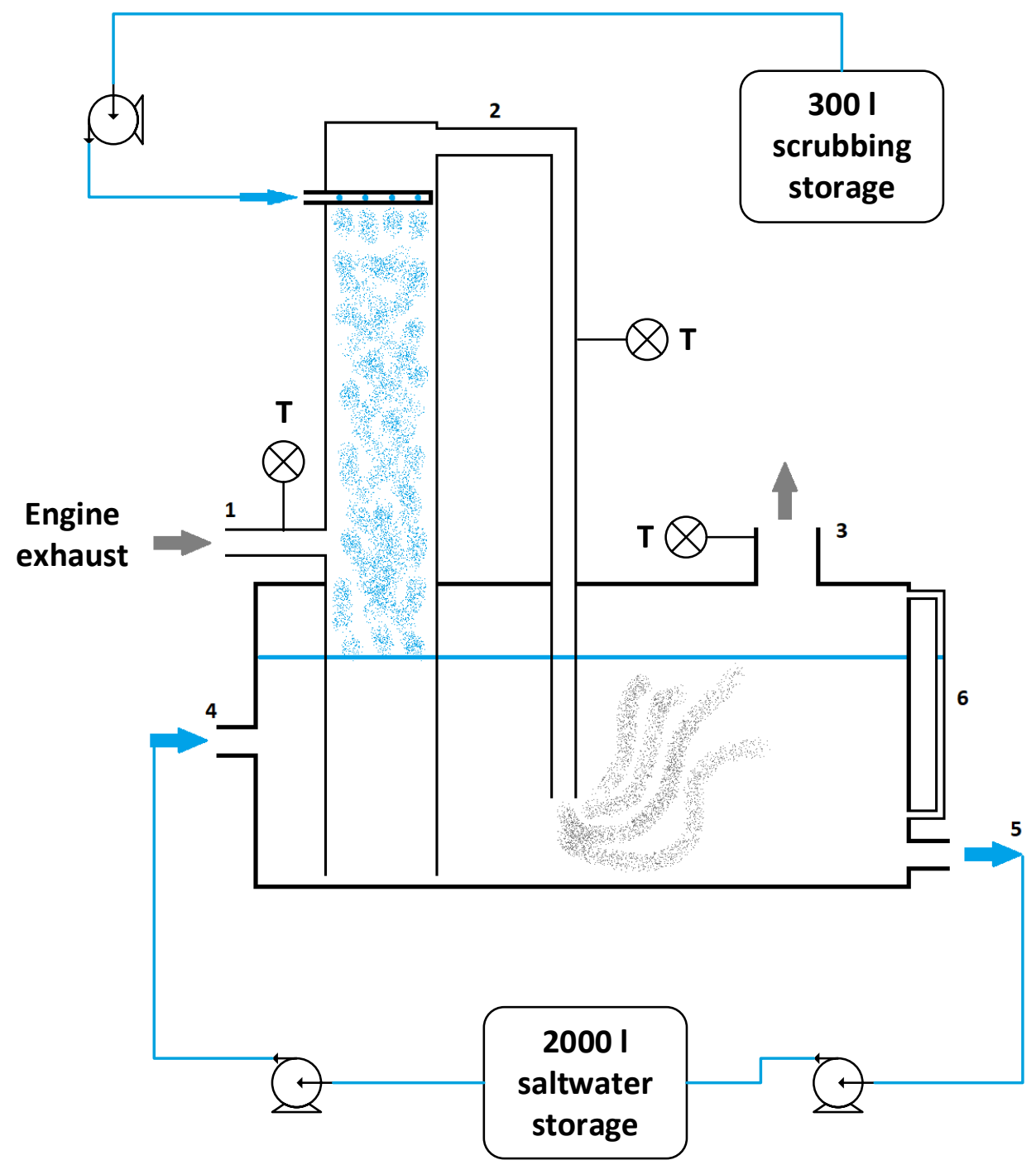

Fig. 3: sketch of the washing tank; 1) engine exhaust gas inlet; 1-bis) engine exhaust gas by-pass; 2) gas scrubber outlet; 3 ) washing tank gas outlet; 4) washing tank water inlet; 5) wash tank water outlet; 6) optical system for checking the water level; 7) washing nozzle water inlet; 8) gas sampling point after scrubber; 9) gas outlet in the washing tank (bubbling point).

\section{Results}

An experimental campaign was carried to analyze the bubbling system in combination with scrubber washing, also verifying the separate effect of the two systems. When activated, the scrubber nozzles were fed at the pressure of 4 bar, the maximum allowed by the pump used. All tests were carried out by reproducing the characteristics of seawater by dissolving $70 \mathrm{~kg}$ of sodium chloride $(\mathrm{NaCl})$ in 2000 liters of washing water (average concentration of seawater is $35 \mathrm{~g} / \mathrm{l})$. 
The first test was carried to understand the effectiveness of the washing system using only seawater while in the second part of the campaign a saline reagent was used for scrubbing. Figure 5 summarizes the results obtained by using only saltwater for both bubbling and scrubbing. This graph shows that the main effect on NO abatement is due to the action of bubbling and that maximum abatement levels are always less than $10 \%$.

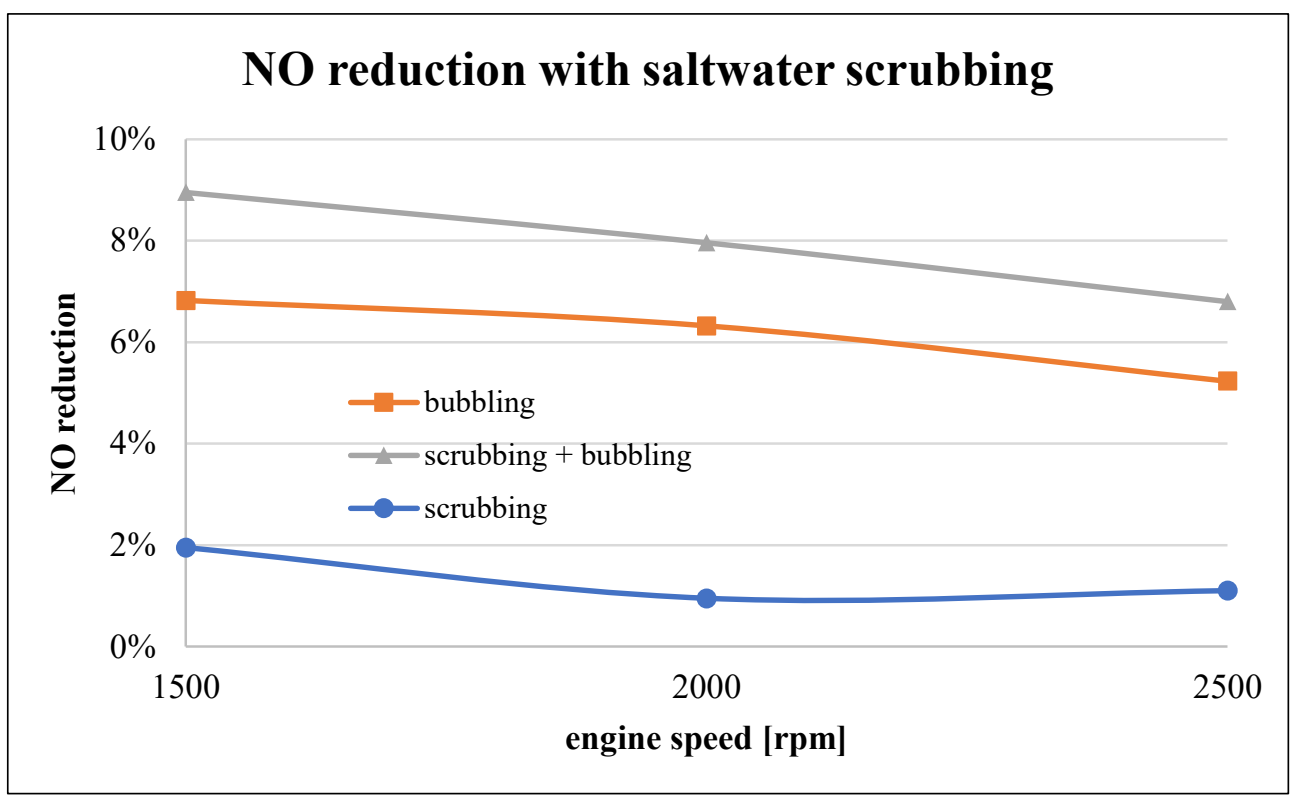

Fig. 5: Bubbling and scrubbing with saltwater

Results showed, unexpectedly, that bubbling has a stronger influence in comparison with scrubber washing which alone contributes to only 1-2\% NO reduction. Overall, the combined scrubbing + bubbling effect allows reductions in NO ranging from about $7 \%$ to a maximum of $9 \%$.

The activation of scrubber washing was also confirmed by the drastic decrease in gas temperatures after scrubber (before entering the bubbling tank) and also with a strong reduction of particulate matter contained in the fumes. This abatement, not in the scope of this research, has not been quantified but was self-evident examining the 2000 liters of saltwater replaced after every test series. After few minutes of bubbling, the saltwater was heavily contaminated by carbonaceous particles.

After these preliminary tests with saltwater, aqueous saline solutions based on sodium hypochlorite $(\mathrm{NaClO})$ were tested and again compared with bubbling in seawater. Two mixtures have been prepared using sodium hypochlorite at $14-15 \%$ :

- low concentration $(0.05 \mathrm{M})$ solution

- $\quad$ higher concentration $(0.2 \mathrm{M})$ solution

$\mathrm{NaClO}$ solutions were used only for scrubbing and saltwater for bubbling. Again, two series of tests were carried out at various engine rotation speeds and full load. For each series of tests, the 2000 liters of saltwater was renewed.

With $0.05 \mathrm{M} \mathrm{NaClO}$ solution, negligible improvements are observed respect to bubbling in saltwater, as reported in Figure 6. Instead, using the $0.2 \mathrm{M}$ solution, the effect of scrubber washing became relevant reaching a reduction of NO up to $26 \%$ (ca. $6 \%$ with only bubbling). 


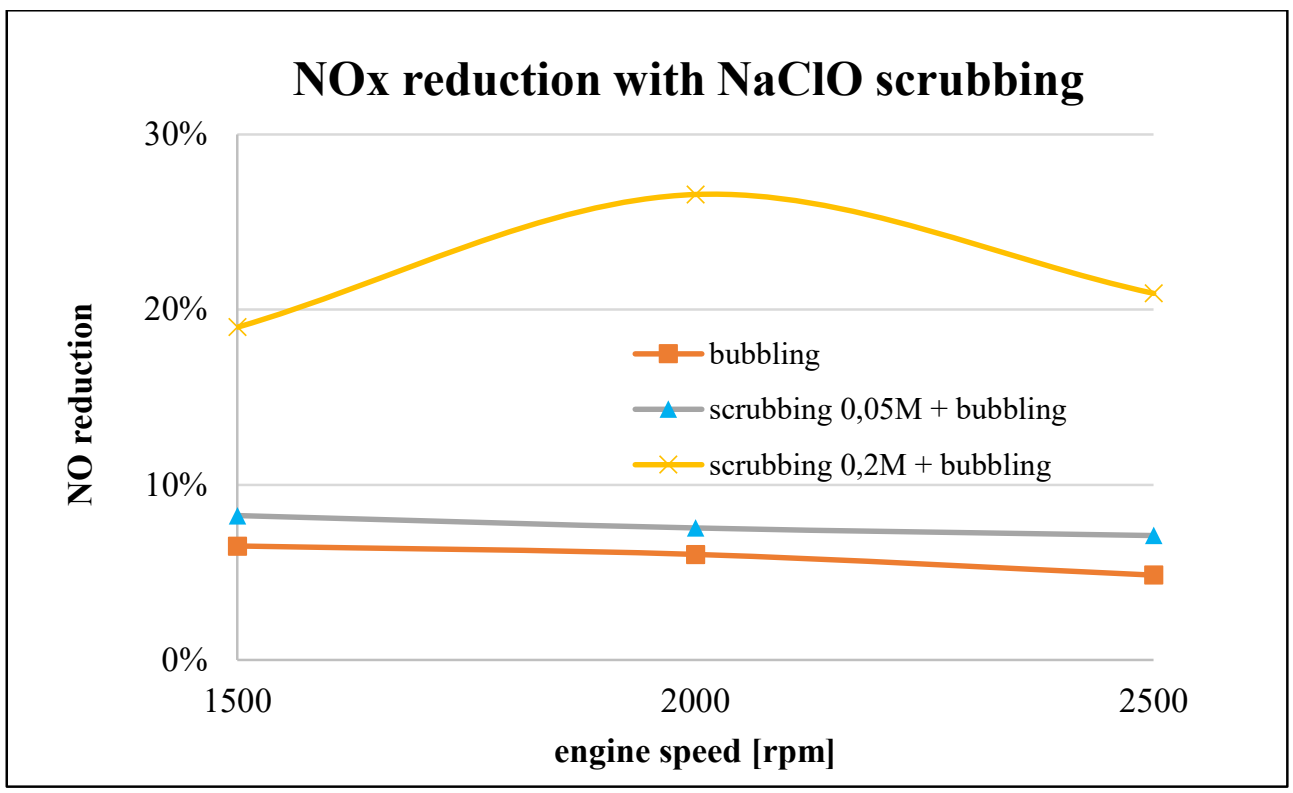

Fig. 6: $\mathrm{NO}$ reduction with bubbling in saltwater and scrubbing with $\mathrm{NaClO}$ solutions $(0.05 \mathrm{M}$ and $0.2 \mathrm{M})$

The concentration of $\mathrm{NaClO}$ highly affects the reduction of $\mathrm{NO}$ thus confirming the oxidizing effect of sodium hypochlorite, as reported in the literature. The influence of scrubber washing with $\mathrm{NaClO}$ solution from a certain concentration $(0.1 \mathrm{M})$ was measured.

It should be noted that for a real application the use of such scrubber washing solutions would result in high consumption of reagents (in this case $\mathrm{NaClO}$ ). Scrubber washing consumption is around 3 liters of solution $0.2 \mathrm{M}$ per $\mathrm{kg}$ of gas emitted by the engine and therefore, considering the mass flow rate of gases of the experimental engine (about $100 \mathrm{~kg} / \mathrm{h}$ at 2500 $\mathrm{rpm}$ ), the total consumption will be about $300 \mathrm{l} / \mathrm{h}$. If a more concentrated solution $(\mathrm{NaClO}$ $14-15 \% \mathrm{vol}$ ) is used for local dilution, the consumption will be about $15 \mathrm{l} / \mathrm{h}$, still very high (a real engine mounted on typical pleasure boats has exhaust flow rates up to $10000 \mathrm{~kg} / \mathrm{h}$ ).

\section{Conclusions}

Recent legislation concerning air pollutant emissions from ships (Tier III) has considerably decreased NOx emission limits for recreational ships with less than 500 gross tonnages and greater than $24 \mathrm{~m}$ load line length (LLL), the so-called "large yachts". For these yachts, which adopt multiple Diesel engines with maximum power ranging from 800 to $2000 \mathrm{~kW}$, the new NOx limit is less than $2 \mathrm{~g} / \mathrm{kWh}$.

The adoption of a classic SCR system with urea injection does not seem the appropriate solutions for this application since diesel engines of large yachts normally operate at low power with exhaust temperatures often well below $300{ }^{\circ} \mathrm{C}$, therefore not sufficient to allow the correct functioning of the SCR.

A collaboration between Sanlorenzo Spa (La Spezia - Italy), one of the world's leading companies in the production of pleasure boats, and the University of Pisa is ongoing with the scope of studying alternative solutions to SCR systems.

A first research program has been dedicated to verifying the possibility of absorbing NO molecules into seawater through the utilization of appropriate aqueous solutions containing targeted saline oxidizing agents. In particular, the study is aimed to identify, from one side, 
the best saline oxidizing agent for an aqueous NO abatement and, from the other, the best washing methodology compatible with the propulsion layouts usually adopted on yachts.

To reproduce the real operating conditions of the engines used on the reference yachts, a washing system, composed of a bubbling tank and a "wet scrubber", has been conceived and built.

The first results obtained using only seawater for bubbling and scrubbing showed that, unexpectedly, bubbling has a stronger influence in comparison to wet scrubbing which alone contributes to only $1-2 \%$ for NO reduction. Overall, the combined scrubbing + bubbling effect allows reductions in NO ranging from about $7 \%$ to a maximum of $9 \%$.

Utilizing a saline solution with a 0.2 molar concentration of $\mathrm{NaClO}$ for the wet scrubbing, followed by bubbling in seawater, a reduction of the NO emissions of about $27 \%$ has been obtained.

As a whole, the present research activity has shown that wet washing systems, with the use of $\mathrm{NaClO}$ saline solutions, have certain effectiveness in reducing the NO present in the exhaust of Diesel engines used on large yachts. However, this abatement is not yet sufficient to meet the emission limits required by current legislation but could be evaluated in combination with other NOx reduction strategies (i.e. EGR).

The activity is continuing with the aim of testing other saline reagents for the wet scrubber, as well as other innovative systems to make NO soluble in seawater.

\section{References}

1. https://www.imo.org/en/OurWork/Environment/Pages/Nitrogen-oxides-(NOx)-\%E2\%80\%93Regulation-13.aspx.

2. M.Guoa, Z.Fua, D. Maa, N.Jia, C.Songa,Q. Liu, “A Short Review of Treatment Methods of Marine Diesel Engine Exhaust Gases", Procedia Engineering 121 ( 2015 ) 938 - 943.

3. M.S. Kang, J. Shin, T.U. Yu, J. Hwang, "Simultaneous removal of gaseous NOx and SO2 by gas-phase oxidation with ozone and wet scrubbing with sodium hydroxide", Chemical Engineering Journal 381 (2020) 122601.

4. S. Zhou, J. Zhou, Y. Feng, Y. Zhu, "Marine Emission Pollution Abatement Using Ozone Oxidation by a Wet Scrubbing Method”, Industrial \& Engineering Chemistry Research 2016, $55,5825-5831$.

5. https://www.feadship.nl/press/oxywash-a-revolutionary-new-clean-technology-for-superyachts.

6. J. Kuropka, Removal of nitrogen oxides from flue gases in a packed column, Environment Protection Engineering (2011) 37, No. 1.

7. J. Yan, F. Zhou, Y. Zhou, X. Wu, Q. Zhu, H. Liu, H. Lu, Wet oxidation and absorption procedure for NOx removal, Environmental Technology \& Innovation 11 (2018) 41-48.

8. Z. Han, S. Yang, D. Zheng, X. Pan, Z. Yan An investigation on NO removal by wet scrubbing using $\mathrm{NaClO}_{2}$ seawater solution SpringerPlus (2016) 5:751.

9. Xi, H., Zhou, S., Zhou, J., Zhang, Z. A novel combined system using Na2S2O8/urea to simultaneously remove $\mathrm{SO}_{2}$ and $\mathrm{NO}$ in marine diesel engine exhaust (2020) Journal of Hazardous Materials, 399, art. no. 123069

10. D. Chandran, M. Khalid, R. Walvekar, N. M. Mubarak, S. Dharaskar, W. Y. Wong and T. C. S. M. Gupta, Deep eutectic solvents for extraction-desulphurization: A review J. Mol. Liq. 275 (2019) 312-322.

11. K. Radošević, M. Cvjetko Bubalo, V. Gaurina Srček, D. Grgas, T. Landeka Dragičević, R. I. Redovniković, Evaluation of toxicity and biodegradability of choline chloride-based deep eutectic solvents Ecotoxicol. Environ. Saf.112(2015) 46-53. 
12. T. Palomba, G. Ciancaleoni, T. Del Giacco, R. Germani, F. Ianni, M. Tiecco, Deep Eutectic Solvents formed by chiral components as chiral reaction media and studies of their structural properties. Mol. Liq. 262 (2018) 285-294;

13. R. Santiago, S. Mossin, J. Bedia, R. Fehrmann, J. Palomar, Methanol-Promoted Oxidation of Nitrogen Oxide (NOx) by Encapsulated Ionic Liquids, Environ. Sci. Technol. 53(2019)1196911978.

14. Nicholas P. Cheremisinoff, "Handbook of Chemical Processing Equipment”, ButterworthHeinemann, 2000.

15. EPA Air Pollution Control Cost Manual (Sixth Edition).

16. Handbook of Air Pollution Control System and Devices, first edition 2012, University Publications.

17. Coulson \& Richardson's “Chemical Engineering Design”, Butterworth-Heinemann, 1999. 